\title{
Carcinogenesis in rats subjected to a new model ureterosigmoidostomy and treated with L-lysine ${ }^{1}$
}

\author{
Alessandra Marques dos Santos ${ }^{\mathrm{I}}$, Joao Paulo Ferreira Coelho ${ }^{\mathrm{II}}$, Camila de Carvalho Juanes ${ }^{\mathrm{II}}$, Rafael Barbosa de Azevedo ${ }^{\mathrm{II}}$, \\ Nayanna de Oliveira Ramos Melo ${ }^{\mathrm{III}}$, Francisco Vagnaldo Fechine Jamacaru ${ }^{\mathrm{IV}}$, Conceição Aparecida Dornelas ${ }^{\mathrm{V}}$ \\ DOI: http://dx.doi.org/10.1590/S0102-865020160120000003 \\ IFellow Master degree, Postgraduate Program in Pathology, Department of Pathology, Universidade Federal do Ceará (UFC), Brazil. Intellectual and \\ scientific content of the study, histopathological examinations, technical procedures, manuscript preparation. \\ II Graduate student, Scientific Iniciation Program, UFC, Fortaleza-CE, Brazil. Technical procedures. \\ ${ }^{\mathrm{II}}$ Graduate student, Scientific Iniciation Program, UFC, Fortaleza-CE, Brazil. Acquisition of data. \\ ${ }^{\text {Iv }} \mathrm{PhD}$, Researcher, Núcleo de Pesquisa e Desenvolvimento de Medicamentos (NPDM), School of Medicine, UFC, Fortaleza-CE, Brazil. Analysis and \\ interpretation of data, statistical analysis. \\ ${ }^{\mathrm{v}} \mathrm{PhD}$, Associate Professor, Department of Pathology, UFC, Fortaleza-CE, Brazil. Conception and design of the study, technical procedures, critical \\ revision, supervised all phases of the study.
}

\begin{abstract}
PURPOSE: To evaluate the effects of L-lysine on the intestinal and urothelial epithelium of rats subjected to ureterosigmoidostomy (new model for surgical carcinogenesis).

METHODS: Forty-two rats, 9 weeks of age, were divided into 6 groups. Animals in groups A, B, C were subjected to ureterosigmoidostomy (US) and treated with L-lysine, celecoxib and $\mathrm{H}_{2} \mathrm{O}$, respectively. Groups D, E and F (non-operated controls) received L-lysine, celecoxib and $\mathrm{H}_{2} \mathrm{O}$, respectively. The L-lysine dose was $150 \mathrm{mg} / \mathrm{kg}$ and that of celecoxib was $20 \mathrm{mg} / \mathrm{kg}$. The colon was analyzed for the presence of aberrant crypt foci (ACF) under a stereomicroscope. The tissue was stained with hematoxylin and eosin and PAS alcian blue.

RESULTS: There were rare ACF, and there was no statistically significant difference between the groups. Histopathologic study of the ureteral epithelium identified moderate to severe urothelial hyperplasia in rats with ureterosigmoidostomy. Transitional hyperplasia in the ureters of animals receiving L-lysine (A) showed an apparent difference compared to the control $(\mathrm{C})(\mathrm{P}=0.2424)$. There was no dysplasia or atypia.
\end{abstract}

CONCLUSION: L-lysine does not promote carcinogenesis of the intestinal and urethelial epithelium of rats subjected to ureterosigmoidostomy at the doses and times studied.

Key words: Urinary Diversion. Carcinogenesis. Lysine. Rats. 


\section{Introduction}

Ureterosigmoidostomy emerged in 1852 as a surgical technique for solving the problem of loss of bladder reservoir function. Other strategies emerged years later, using various gastrointestinal segments for different patients with urinary disorders.

The first case of cancer associated with ureterosigmoidostomy was published in $1929^{1}$ and since then, there have been many reports in the literature of tumors in other types of urinary diversions with colon and sigmoid segment and cystoplasty with gastrointestinal segments.

A systematic review in 2012 found that ureterosigmoidostomy is a well-documented risk factor for cancer, where the histologic type most found was adenocarcinoma; the incidence ranged from 2 to $41 \%$, with a latency period of 10 to 30 years, and the risk of occurrence of cancer was between 80-7000 times higher than in the general population ${ }^{2}$.

The real factors that lead to carcinogenesis with ureterosigmoidostomy are still unknown. Several mechanisms have been proposed to explain its pathophysiology, such as chronic inflammation, recurrent infections ${ }^{3}, \mathrm{pH}$ changes, nitrosamine production by bacteria, and genetic instability of the anastomotic areas $^{4}$, among other cases, but there are many variables that have not been uncovered.

Aberrant crypts are characterized by irregularly shaped glands (crypts), with enlarged luminal opening and cell hyperplasia. Aberrant crypt foci (ACF) are groupings of aberrant crypts $^{5}$ Aberrant crypts may show dysplasias. It is known that the dysplastic ACF are at great risk for malignant transformation.

The known route established for colon carcinogenesis with formation of ACF, is the same pathway of surgical carcinogenesis in urinary diversions? This response could be very interesting at this moment, where the study of ACF could be used in preventive clinical evaluation of patients undergoing a urinary diversion.

Various authors have reported the inhibitory effect of celecoxib on $\mathrm{ACF}^{6}$. The inhibition and reduction of COX-2, NFk $\beta$ and interleukins in rats and the protection of bone marrow cells subjected to chemical carcinogenesis in different organs have been observed by various authors ${ }^{7,8}$.

There are reports of a promoting effect on bladder carcinogenesis in rats with carcinogenesis chemical and L-lysine, an essential amino acid ${ }^{9}$.
The objective of this study was to evaluate the effects of L-lysine on the intestinal and urothelial epithelium of rats subjected to ureterosigmoidostomy in a new model of surgical carcinogenesis.

\section{Methods}

This study was presented to and approved by the Ethics in Animal Reseach Committee, Universidade Federal do Ceará, under Protocol No. 80/2011 and was in accordance with the principles of the ethics in animal experimentation adopted by the Brazilian College of Animal Experimentation (COBEA).

We used a total of 42 female Wistar rats, with 9 weeks of age, weighing on average 190 grams, which were obtained from the Central Animal Laboratory of the Federal University of Ceará. The animals were housed in polypropylene cages, 5 to 6 animals per cage, which was lined with autoclaved white pine wood shavings. They were given Luvital basic pelleted feed and water ad libitum. The animals were kept at a temperature around $25^{\circ} \mathrm{C}$, under a 12-h light/dark cycle, with continuous exhaust system.

\section{Maintenance conditons of animals}

The cages were cleaned and the wood shavings changed every 3 days. The animals were dewormed with Petzi Plus suspension and injectable Imovec before surgery.

\section{Drugs used}

\section{Celecoxib}

Celecoxib was obtained from Celebra $200 \mathrm{mg}$ capsules (Pfizer) and administered at doses of $20 \mathrm{mg} / \mathrm{kg}$ by gavage.

\section{L-Lysine}

L-Lysine $\left(\mathrm{C}_{6} \mathrm{H}_{14} \mathrm{~N}_{2} \mathrm{O}_{2}\right.$ HCL, CAS- 657-27-2) was dissolvedd in $1 \mathrm{ml}$ of distilled $\mathrm{H}_{2} \mathrm{O}$ and administered at doses of $150 \mathrm{mg} / \mathrm{kg} /$ day by gavage.

\section{Experimental design}

The 42 animals were distributed into 3 experimental groups, A, B and C, each with 8 animals, and 3 control groups, D, $\mathrm{E}$ and $\mathrm{F}$, each with 6 animals, according to the experimental design shown in Figure 1. 


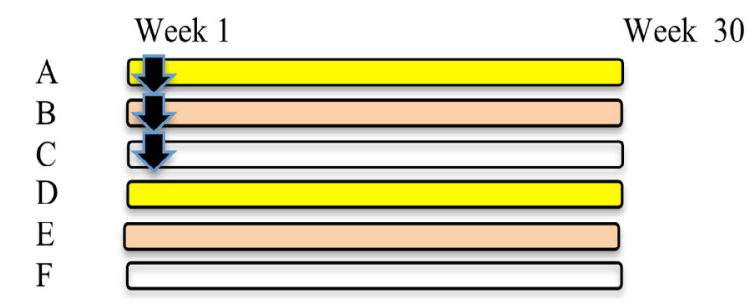

Ureterosigmoidostomy

L Lysine

Celecoxib

$\mathrm{H}_{2} \mathrm{O}$

FIGURE 1 - Experimental design.

\section{Surgical procedures}

The surgical procedure was performed under intraperitoneal anesthesia with ketamine and xylazine at 100 and $10 \mathrm{mg} / \mathrm{kg}$ body weight, respectively.

The animals underwent a new surgical technique of ureterosigmoidostomy. The surgery was performed under a stereomicroscope, using only one of the ureters, with dissection and cutting left ureter near the bladder. The ureter with a needled 70 suture with repair was pierced through a meso in the left uterine horn, aimed at approaching the distal colon. A tunnel was made in the distal colon wall using a hypodermic needle up to the intestinal lumen after a path of $6 \mathrm{~mm}$. The ureter was guided through the tunnel with a needled Vicryl 70 suture transfixing the end of the ureter. After this tunnel, the ureter was buried and fixed to the wall with and opening to the intestinal lumen (Figure 2a-d).
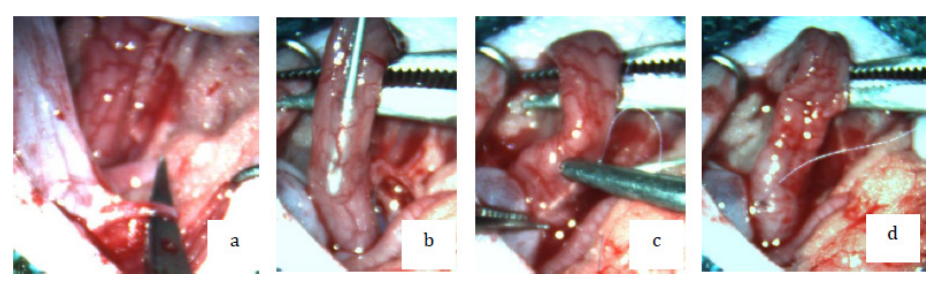

FIGURE 2 -a. Dissection of distal ureter. b. Tunnel with hypodermic needle. c. Guidance of the ureter in the tunnel with a needled suture. d. Point fixing intraintestinal ureter on wall.

The animals were subjected to zero diet preoperative and postoperative in the 12 night hours before the procedure, and only water ad libitum for 24 hours postoperatively. Mineral oil, $1 \mathrm{ml}$, was administered by gavage two days prior to surgery and maintained for four postoperative days (POD). Ceftriaxone was administered intramuscularly, $100 \mathrm{mg} / \mathrm{kg}$ body and ketoprofen intramuscularly at $5 \mathrm{mg} / \mathrm{kg}$ at 4 POD.

\section{Clinical observation of animals}

Clinicalobservation with respect to ureterosigmoidostomy function was based on whether or not there was urine elimination through the anal region of the animal (functioning or not)

\section{Sacrifice of animals}

At 30 weeks after surgery, the animals were evaluated with regard to abdominal cavity, death and necropsy. These procedures were performed under anesthesia with ketamine and xylazine at doses of $100 \mathrm{mg} / \mathrm{kg}$ and $10 \mathrm{mg} / \mathrm{kg}$, respectively. The abdominal wall was opened with a median longitudinal xypho-pubic incision, involving skin, subcutaneous tissue and musclature to the abdominal cavity. Suvey of the cavity was carried out methodically, noting areas of uretercolic anastomosis, (ureterosigmoidostomy), kidneys bilaterally and other abdominal viscera. The animals were then killed with 3 more doses of ketamine and xylazine.

\section{Macroscopy}

In assessing the ureterosigmoidostomy, the colon was resected along with the left ureter and left kidney, open the antimesocolic border, from rectum to cecum, washed with saline extended on Kraft paper, keeping the ureter and left kidney in the exact position in which they were and rolled up along the axis and fixed in $10 \%$ buffered formalin.

\section{Microscopy}

After 24 hours of fixation, the colon of the ureterosigmoidostomy was stained with methylene blue in $0.1 \mathrm{M}$ PBS (phosphate-buffered saline) for $1 \mathrm{~min}$. A stereomicroscope was used to for counting $\mathrm{ACF}^{5,10}$. along its entire length, per segment of the colon (distal, middle and proximal)

Areas of colovesical and colo-urethral and ureteral anastomoses were cleaved and sent for histological processing, embedding in paraffin and staining with hematoxylin and eosin and PAS alcian blue.

Histopatologic lesions were classified according to the international classification of the urinary system of mice, published by the Agency for Research on Cancer ${ }^{11}$, with updating and criteria of $\mathrm{Oyasu}^{12}$. 


\section{Statistical analysis}

The histopathologic data were analyzed with Statistical Packcage for the Social Sciences (SPSS) version 17.0 for Windows, considering a 95\% confidence interval. Categorical data were expressed as absolute frequency and percentage and evaluated by the Fisher exact or Pearson chi-square test. Quantitative data were expressed as mean and standard deviation and assessed by the Kruskall-Wallis or Mann-Whitney test

\section{Results}

There was a decrease in body weight in all rats after the surgical procedure. The curve increased up to $200 \mathrm{~g}$ and plateaued at about $250 \mathrm{~g}$, where afterwards, there were no differences between groups.

\section{Mortality of animals subjected to ureterosigmoidos- tomy}

There were 7 deaths in total: 2 animais in group A (lung abscess and pyonephrosis at 15 weeks, and pneumonia at 18 weeks); 2 animals in group B (urinary fistula to abdominal cavity at 9 weeks, lung abscesso at 15 weeks); and 3 animals in group $\mathrm{C}$ (peritonitis with fecaloma at 9 weeks, hemorrhagic pulmonary pneumonia at 16 weeks, and pyonephrosis at 21 weeks).

\section{Macroscopy}

A macroscopic study of ureterosigmoidostomies showed the right kidney and ureters without particularities. In the left kidney with ureter implanted in the descending colon, there was moderate to marked ureterohydronephrosis (Figure $3 \mathrm{a}, \mathrm{b}$ ) in most animals, with many having pyonephrosis and microabscesses. In loco observation showed kidney expression and urine output through the ureteral orifice in the colon (functionality): $66 \%$ in group A, 57\% in group B and $71.4 \%$ in group C. Obstruction by ureteral calculus was found in only one of the dilated ureters.

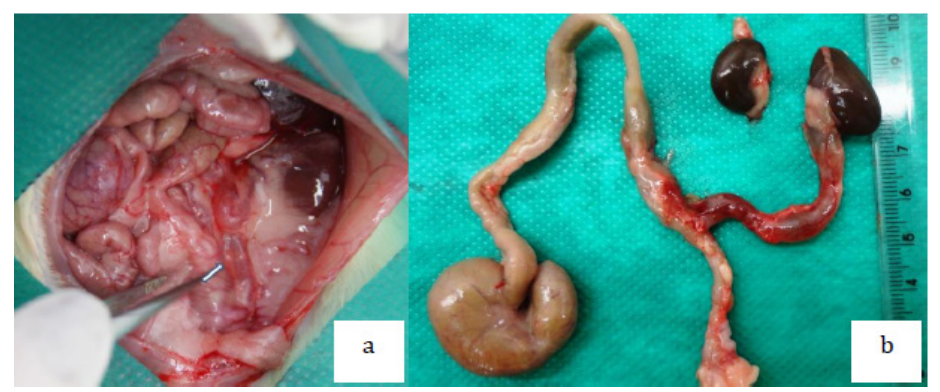

FIGURE 3 - a. Dilated ureter implanted in the descending colon (arrow). b. Closed colon and left ureterosigmoidostomy with dilated ureter, left kidney and right kidney.

\section{Microscopy by $H E$}

In the intraureteral tract of groups A, B and C, there were projections of transitional hyperplasia of the flat and papillary and nodular type with mild, moderate or severe intensity (Tables 1 and 2). A transitional papilloma was found in the ureter in 3 animals. An inflammatory polyp was observed in the colonic mucosa (Figure 4 a-c). There was inflammatory infiltrate consisting of lymphocytes in the region of the ureteral mucosa and submucosa and among the intestinal crypts, with a marked decrease in mucins in crypts cells in ureterocolic anastomoses No dysplasia or atypical cells were observed.

TABLE 1 - Histopathologic lesions found in groups A, B and C. Data expressed as absolute (n) and relative (\%) frequencies and analyzed by Chi-square test.

\begin{tabular}{|c|c|c|c|c|c|c|c|}
\hline \multirow{2}{*}{$\begin{array}{l}\text { Histopatho- } \\
\text { logic } \\
\text { findings }\end{array}$} & \multicolumn{2}{|c|}{ Group A } & \multicolumn{2}{|c|}{ Group B } & \multicolumn{2}{|c|}{ Group C } & \multirow{2}{*}{$\begin{array}{c}\text { Sig- } \\
\text { nificance } \\
\text { (Chi- } \\
\text { square) }\end{array}$} \\
\hline & $\mathrm{n}$ & $\%$ & $\mathrm{n}$ & $\%$ & $\mathrm{n}$ & $\%$ & \\
\hline \multicolumn{8}{|l|}{ Inflammation } \\
\hline Absent & 1 & 16.67 & 1 & 16.67 & 0 & 0.00 & $\begin{array}{c}P= \\
0.5698\end{array}$ \\
\hline Present & 5 & 83.33 & 5 & 83.33 & 6 & 100.00 & \\
\hline Total & 6 & 100.00 & 6 & 100.00 & 6 & 100.00 & \\
\hline
\end{tabular}

Degree of

inflammation

\begin{tabular}{|c|c|c|c|c|c|c|c|}
\hline Absent & 1 & 16.67 & 1 & 16.67 & 0 & 0.00 & $\begin{array}{c}P= \\
0.1644\end{array}$ \\
\hline Mild & 0 & 0.00 & 1 & 16.67 & 3 & 50.00 & \\
\hline Moderate & 0 & 0.00 & 1 & 16.67 & 2 & 33.33 & \\
\hline Severe & 5 & 83.33 & 3 & 50.00 & 1 & 16.67 & \\
\hline Total & 6 & 100.00 & 6 & 100.00 & 6 & 100.00 & \\
\hline \multicolumn{8}{|l|}{ Papilloma } \\
\hline Absent & 4 & 66.67 & 6 & 100.00 & 5 & 83.33 & $\begin{array}{c}P= \\
0.3012\end{array}$ \\
\hline Present & 2 & 33.33 & 0 & 0.00 & 1 & 16.67 & \\
\hline Total & 6 & 100.00 & 6 & 100.00 & 6 & 100.00 & \\
\hline \multicolumn{8}{|l|}{ Polyp } \\
\hline Absent & 6 & 100.00 & 5 & 83.33 & 6 & 100.00 & $\begin{array}{c}P= \\
0.3469\end{array}$ \\
\hline Present & 0 & 0.00 & 1 & 16.67 & 0 & 0.00 & \\
\hline Total & 6 & 100.00 & 6 & 100.00 & 6 & 100.00 & \\
\hline \multicolumn{8}{|l|}{$\begin{array}{l}\text { Degree } \\
\text { of ureteral } \\
\text { lyperplasia }\end{array}$} \\
\hline Mild & 0 & 0.00 & 1 & 16.67 & 0 & 0.00 & $\begin{array}{c}P= \\
0.1797\end{array}$ \\
\hline Moderate & 1 & 16.67 & 1 & 16.67 & 4 & 66.67 & \\
\hline Severe & 5 & 83.33 & 4 & 66.67 & 2 & 33.33 & \\
\hline Total & 6 & 100.00 & 6 & 100.00 & 6 & 100.00 & \\
\hline
\end{tabular}


TABLE 2 - Intensity of ureteral hyperplasia in groups A and C. Data expressed as absolute (n) and relative (\%) frequencies and analyzed by Fisher's exact test.

\begin{tabular}{cccccccc}
\hline $\begin{array}{c}\text { Degree of } \\
\text { ureteral } \\
\text { hyperpla- }\end{array}$ & Group A & Group C & Total & $\begin{array}{c}\text { Sig- } \\
\text { nificance }\end{array}$ \\
sia & $\%$ & $\mathrm{n}$ & $\%$ & $\mathrm{n}$ & $\%$ & $\begin{array}{c}\text { (Fisher's } \\
\text { exact test) }\end{array}$ \\
\hline $\begin{array}{c}\text { Mild / } \\
\text { moderate }\end{array}$ & 1 & 16.67 & 4 & 66.67 & 5 & 41.67 & \\
Severe & 5 & 83.33 & 2 & 33.33 & 7 & 58.33 & $\mathrm{P}=0.2424$ \\
Total & 6 & 100.00 & 6 & 100.00 & 12 & 100.00 & \\
\hline
\end{tabular}

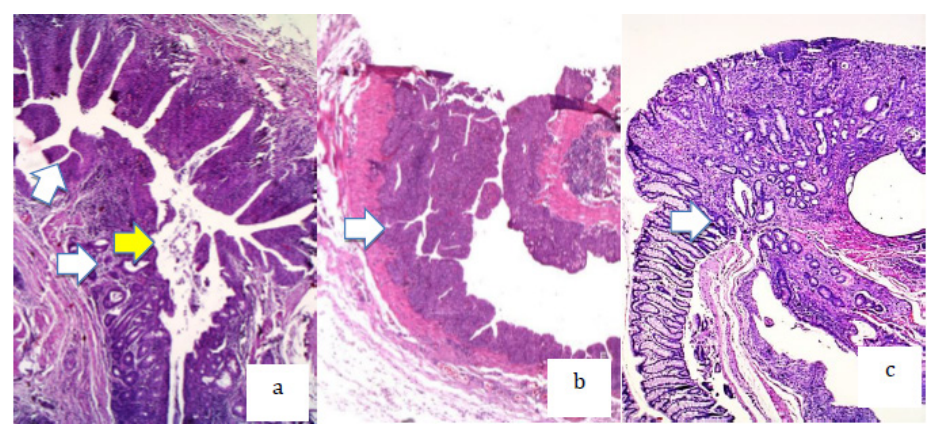

FIGURE 4 - a. Ureteral tract (white arrows) and in its interior, papillary projections with vascular axes (yellow arrows). b. Transitional papilloma in ureter (arrow). c. Inflammatory polyp in colon by ureterocolic anastomosis (arrow). HE x50.

\section{Microscopy with PAS - Alcian Blue}

PAS-alcian blue staining showed a marked decrease in goblet cells and mucin production in the crypts in the epithelium of the colon close to the ureterosigmoidostomy region when compared with the colon of non-operated animals (Figure $5 \mathrm{a}, \mathrm{b}$ ).
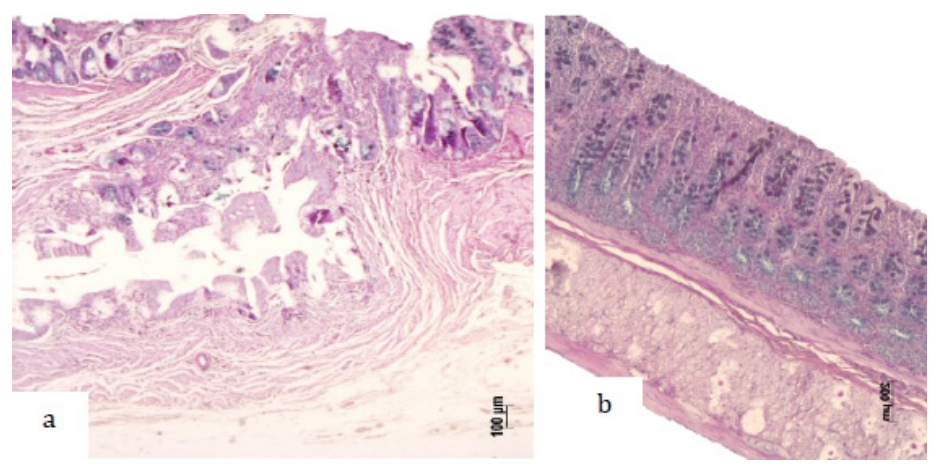

FIGURE 5 - a. Region of colon ureterocolic, decrease in goblet cells - PAS - alcian blue. b. Colon of rat in Group IX (control) - rat 3 - PAS alcian blue, $x 100$.

\section{Aberrant crypt foci $(A C F)$ and number of aberrant crypts}

ACF found with a stereomicroscope in animals of groups A, B, C, D, E and F, considering the proximal, middle and distal segments (Table 3 ) were compared and the data evaluated by the chi-square test, which showed no statistically significant difference between the groups for the presence of ACF $(p=0.0794)$ Comparisons between groups $\mathrm{D}, \mathrm{E}$ and $\mathrm{F}$ showed $\mathrm{p}=0.3776$ and between $A, B$ and $C, p=0.9558$. Paired comparisons carried out between $\mathrm{C}$ and $\mathrm{F}$ showed $\mathrm{p}=0.1818$, between $\mathrm{B}$ and $\mathrm{E}, \mathrm{p}=0.1818$, and between $\mathrm{A}$ and $\mathrm{D}, \mathrm{p}=0.2657$, thereby without statistical significance.

TABLE 3 - Foci of aberrant crypts in animals of groups A,B,C,D,E and F considering all segments: proximal, middle and distal.

\begin{tabular}{cccc}
\hline \multirow{2}{*}{ Group } & \multicolumn{2}{c}{ Aberrant crypt foci } & Total \\
& Present & Absent & 7 \\
A & 4 & 3 & 6 \\
B & 3 & 3 & 6 \\
C & 3 & 3 & 6 \\
D & 1 & 5 & 5 \\
E & 0 & 5 & 6 \\
F & 0 & 6 & 36 \\
Total & 11 & 25 & \\
\hline
\end{tabular}

Statistical analysis on the number of aberrant crypts was also performed for groups A, B, C, D, E, and F, considering the proximal, middle and distal segments. The data were expressed as median, interquartile range and minimum and maximum values. The Kruskal-Wallis test was used to compare the six groups, in combination with Dunn's multiple comparison test, to check for differences between the groups in pairs. No statistically significant differences were found between the groups studied $(p=0.0902)$ (Figure 6).

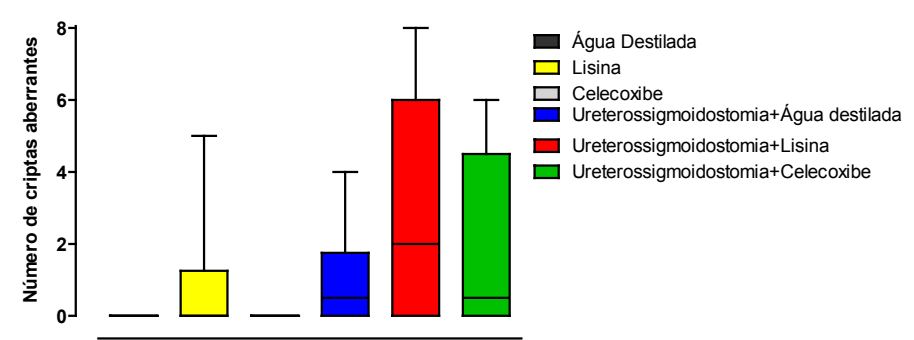

FIGURE 6 - Number of aberrant crypts in groups A , B, C, D and E, considering the proximal, middle and distal segments. 


\section{Discussion}

As reported, the first case of carcinogenesis in ureterosigmoidostomy was described in 1929 However, only after knowing the first case of neoplasia in a uretero-ileal diversion, studies were initiated on oncogenesis in urinary diversions, since the feces could not have been the causative factor ${ }^{13}$.

$\mathrm{Käble}^{14}$, after a case review, made some recommendations regarding ureterosigmoidostomy, due to the incidence of cancer found in this urinary diversion: ureterosigmoidostomy should not be performed in patients who are expected to have a survival beyond 15 years; ureterosigmoidostomy should not be performed as a temporary solution; and if the later happens, it should not be prolonged beyond 15 years.

The experimental work carried out by Crissey et $a l .{ }^{15}$ became the classic model for this study. They used rats as experimental models, which underwent vesicosigmoidostomy combined with the use of carcinogens in the colon and bladder (dimethylhydrazine and FANFT). In $80 \%$ of the animals, there was the presence of neoplastic changes in colonic epithelium near the anastomotic area. However, in the place where it a proximal colostomy was performed combined with vesicosigmoidostomy, there were no neoplastic epithelial changes.

The ureterosigmoidostomy model used in this study was developed because of the difficulties encountered with respect to high morbimortality found by these same authors, while conducting ureterosigmoidostomies (vesicosigmoidostomies) following the classic model of Crissey et al. ${ }^{16}$, in which mortality at 8 weeks reached $45 \%$

In animals subjected to the new model of ureterosigmoidostomy by the same authors ${ }^{16}$ at 8 weeks, mortality was only $8.3 \%$. At 30 weeks of follow-up (time at least 3 times longer), mortality was only $29 \%$. The new model was used to allow a longer period of observation (as is the long latency period for the development of carcinogenesis in urinary diversions), to reduce the number of animals used for ethical reasons as well Implanting only one ureter in the colon allowed the animal to have a greater survival, since it would thus have a greater chance of preserving contralateral kidney function, in case of loss of one renal functional unit with ureterosigmoidostomy.

It should be noted that the time of observation in our study was 30 weeks the equivalent of 7.5 months. In adulthood, every month of the animal is approximately equivalent to 2.5 human years ${ }^{17}$. Therefore, our animals would have a surgery time of about 19 years in humans.

The ureter in animals subjected to ureterosigmoidostomy
(Groups A, B and C) had histologic lesions with transitional cell hyperplasia apparently more pronounced in animals that received L-lysine compared to the control group of animals. The Fisher test used to compare these data showed $\mathrm{P}=0.2424$. Thus, there was no statistical significance. We questioned whether the increased observation time would favor the increase in hyperplasia in animals that received L-lysine.

In some animals, we observed transitional cell papilloma with squamous metaplasia and inflammatory polyps, and these lesions are also described as sequential in the histogenesis of bladder carcinogenesis in rodents ${ }^{12}$. Would it just be reactive? Or would we have here a histogenesis process of ureteral carcinogenesis already established?

There was intense inflammatory infiltrate consisting predominantly of lymphocytes in the region of the mucosa and submucosa, ureter and colon, even in animals with nonfunctioning ureteral implant in groups A, B and C. This brings us to some reports of malignant neoplasia in the ureteral stump left in the sigmoid in the case of ureterosigmoidostomy (for benign conditions at short time intervals), where the patients were considered for the construction of another urinary reservoir, leaving the sigmoid free of urine and the ureteral stump implanted there ${ }^{18}$.

The question is could the epithelial changes be reactive to pronounced chronic inflammation and could they thus result in future ureteral carcinogenesis?

Through immunohistochemistry, there have been studies of the mucins of the cervix of normal individuals and patients with urinary diversion using alcian blue staining in biopsied tissue from the sigmoid. Differences were noted in the distribution of mucins, sialomucin and sulfomucin. In the normal colonic mucosa, sialomucin was observed on top of the crypts and sulfamucin was visualized in the middle and lower portions. In patients with ureterosigmoidostomy, there is a total replacement by sialomucin (which stains blue), resulting in the designattion "blue crypt"19. These changes were also observed in patients with cervical adenocarcinoma and ulcerative rectocolitis ${ }^{19}$.

Our results in the observation of mucins by histochemistry with PAS - alcian blue showed in a diffuse manner, that there was a marked decrease in mucin content in goblet cells in regions of colonic epithelium near the ureterocolic anastomosis of animals of groups A, B and C.

Regarding the assessment of colon carcinogenesis, our study focused not only on histopathologic changes, such as stereomicroscopy of precancerous lesions classically known as aberrant crypts and also ACF in animals subjected to ureterosigmoidostomy (groups A, B and C). 
The ACF was originally described by Bird in 1987 in rats with colon chemical carcinogenesis. However, a few years later, the same author suggested and others confirmed that AFC in fact was part of the sequential evolution of colon carcinogenesis, which can become dysplastic, which can give rise to adenomas and colorectal carcinoma in that order, serving then as a model of early lesions, that is, pre-neoplastic lesions in colorectal carcinogenesis ${ }^{20,21}$. There is a prevalence of ACF of 53.6\% in normal individuals over 50 years, $90 \%$ in patients with adenoma and $100 \%$ in patients with colorectal carcinoma ${ }^{22}$.

Is the known established pathway of colon carcinogenesis with the formation of ACF is the same as that of surgical carcinogenesis in urinary diversions? This response could be very interesting at the moment, where studies on ACF could be used in the preventive clinical evaluation of patients undergoing urinary diversions.

Daher et $a l .^{23}$ studied colon mucin antigen by immunohistochemistry in rats subjected to ureterosigmoidostomy and found that colorectal chemical carcinogenesis by dimethyl hydrazine, differed from carcinogenesis in ureterosigmoidostomy.

Do ACF occur with ureterosigmoidostomy in rats? What is known so far is the presence of ACF in chemical carcinogenesis and other colon diseases with potential for malignant transformation. In a recent work by Dornelas et al. ${ }^{16}$, in the classic experimental model of ureterosigmoidostomy ${ }^{15}$, followed for 8 weeks aberrant crypts were detected both in Wistar rats subjected to vesicosigmoidostomy for 8 weeks and the nonoperated control group, and there was no statistically significant difference in animals receiving L-lysine at the same doses as in our study. There is no other report in the literature.

Is L-lysine a promoter in carcinogenesis of the colon and/or ureter in ureterosigmoidostomy? Considering that ACF are precursor lesions of colon, does L-lysine increase the occurrence of ACF?

The cancer promotion stage is effected by promoters in initiated cells. Promoters are able to lead initiated cells to proliferation and then to develop additional mutations. Promoters are not capable of producing mutations, but the condition of maintaining cell proliferation is required so that they can contribute to carcinogenesis ${ }^{24}$. Dornelas et $a l .{ }^{9}$, in a recent study, found that L-lysine, has a promoter action in bladder carcinogenesis in rats subjected to chemical carcinogenesis by BBN.

$\mathrm{ACF}$ were observed in nonoperated animals given only L-lysine (Group F), where only 1 animal developed 2 ACF of 1 of 2 crypts and another of 3 crypts. Comparing this control with the group of animals subjected to ureterosigmoidostomy who received L-lysine (group A), there was no statistical significance. Therefore, there was no promotion of carcinogenesis according to ACF analysis.

The administration of celecoxib in the promotion/ progression stage inhibits tumor growth induced by azoxymethane, indirectly suggesting that the chemopreventive efficacy of this agent is achieved even during the later stages of the development of colon cancer. Vaish and Sanyal ${ }^{25}$ suggested that this occurs via inhibition of the expression and signaling of NF-kB and Jak3/ Stat3, inhibiting cytokines and thereby inhibiting inflammation and carcinogenesis ${ }^{25}$. In our study, the animals in group B, who underwent ureterosigmoidostomy and received celecoxib, showed no decrease in $\mathrm{ACF}$, compared to the control group (E group) subjected to ureterosigmoidostomy and given distilled water.

Some authors have observed a correlation of cancer with the number of ACF, while others with the multiplicity of crypts ${ }^{26}$. In our study we found no multiplicities of aberrant crypts. Most ACF contained only one crypt and had no dysplasia. Would an ACF with 1 crypt without dysplasia be of importance in colon carcinogenesis?

In the animals of groups $\mathrm{C}$ (subjected to ureterosigmoidostomy), with regard to the number of aberrant crypts and the number of ACF, there was no statistical significance when compared with its control (group F), whose animals did not undergo surgery and received only water, indicating that the appearance of these foci were not influenced by the surgery, at least in the observation time of 30 weeks.

Although the significance of the finding of isolated ACF without dysplasia is still unknown, there are reports of ACF involution, as well as adenomas. Also, the emergence of spontaneous ACF has been described in Fischer 344 rats without the use of a carcinogen ${ }^{27}$. Recently, Burlamaqui et $a l .^{28}$, using azoxymethane for experimental colon carcinogenesis, reported the presence of ACF, albeit scarce, in rats that received no carcinogen. Our results suggest that aberrant crypts do not follow the model of colon carcinogenesis in rats subjected to ureterosigmoidostomy.

\section{Conclusion}

L-lysine has no promoter action in the carcinogenesis of intestinal and urothelial epithelium in rats subjected to ureterossigmoidostomy at the doses and times investigated.

\section{References}

1. Hammer E. Cancer du colon sigmoide dix ans après implantation des uretères d'une vessie exstrophiée. JUrol Nephrol. 1929;28(1):260-3. 
2. Mehta RS, Ennis P, Whitten J. Ureterosigmoidostomy associated signet ring colon cancer presenting as hip pain. J Gastrointest Cancer. 2012 Mar;43(1):122-7. doi: 10.1007/s12029-010-9184-6.

3. Chester JF, Gaissert HA, Ross JS, Malt RA, Weitzman SA. N-[4(5-nitro-2-furyl)-2-thiazolyl] formamide-induced bladder cancer in mice: augmentation by sutures through the bladder wall. J Urol. 1987 Apr;137(4):769-71. PMID: 356034.

4. Gitlin JS, Wu XR, Sun TT, Ritchey ML, Shapiro E. New concepts of histological changes in experimental augmentation cystoplasty: insights into the development of neoplastic transformation at the enterovesical and gastrovesical anastomosis. J Urol. 1999 Sep;162(3 Pt 2):1096-100. PMID: 10458439.

5. Bird RP. Observations and quantification of aberrant crypts in the murine colon treated with a colon carcinogen: preliminary findings. Cancer Lett. 1987 Oct 30;37(2):147-51. PMID: 3677050.

6. Do K, Barnard GF. Effect of concomitant polyethylene glycol and celecoxib on colonic aberrant crypt foci and tumors in F344 rats. Dig Dis Sci. 2005 Jul;50(7):1304-11. doi: 10.1007/s10620-0052777-4.

7. Dornelas CA, Cavalcanti BC, Magalhães HI, Jamacaru FV, Furtado FN, Juanes Cde C, Melo Nde O, Moraes MO. Potential chemoprotective effects of green propolis, L-lysine and celecoxib on bone marrow cells and peripheral blood lymphocytes of Wistar rats subjected to bladder chemical carcinogenesis. Acta Cir Bras. 2014 Jul;29(7):423-8. doi: 10.1590/S0102-86502014000700003.

8. Negi AK, Renuka, Bhatnagar A, Agnihotri N. Celecoxib and fish oil: a combination strategy for decreased inflammatory mediators in early stages of experimental mammary cancer. Inflammopharmacology. 2016 Feb;24(1):11-22. doi: 10.1007/s10787-015-0259-7.

9. Dornelas CA, Fechine-Jamacaru FV, Albuquerque IL, Magalhães HI, Souza AJ, Alves LA, Almeida PR, Lemos TL, Castro JD, Moraes ME, Moraes MO. Chemoprevention with green propolis extracted in L-lysine versus carcinogenesis promotion with L-lysine in N-butyl-N-[4-hydroxybutyl] nitrosamine (BBN) induced rat bladder cancer. Acta Cir Bras. 2012 Feb;27(2):185-92. doi: 10.1590/ S0102-86502012000200015.

10. Burlamaqui IM, Dornelas CA, Escalante RD, Mota DM, Mesquita FJ, Carvalho ER, Veras LB, Rodrigues LV. Optimization of visibility and quantification of aberrant crypt foci in colonic mucosa in Wistar rats. Acta Cir Bras. 2010 Apr;25(2):148-52. doi: 10.1590/S010286502010000200005.

11. IARC - International Classification of rodent tumours. Part I: The rat. 3 - urinary system. IARC Scientific Publications; 1992. p.1-46.

12. Oyasu R. Epithelial tumours of the lower urinary tract in humans and rodents. Food Chem Toxicol. 1995 Sep;33(9):747-55. doi: 10.1016/0278-6915(95)00042-Z.

13. Shousha S, Scott J, Polak J. Ileal loop carcinoma after cystectomy for bladder exstrophy. Br Med J. 1978 Aug 5;2(6134):397-8. PMID: PMC1609091.

14. Kälble T. Continent urinary diversion - ureterosigmoidostomy: 50 years follow-up. Aktuelle Urol. 2013 Nov;44(6):430-1. doi: 10.1055/s-0033-1363050.

15. Crissey MM, Steele GD, Gittes RF. Rat model for a carcinogenesis in ureterosigmoidostomy. Science. 1980 Mar 7;207(4435):1079-80. doi: 10.1126/science.7355272.

16. Dornelas CA, Santos AM, Correia ALO, Juanes CC, Coelho JPF, Cunha BL, Maciel AVV, Fechine Jmacaru FV. Bladder carcinogenesis in rats subjected to ureterosigmoidostomy treated with L-lysine. Rev Col Bras Cir. 2016 Mar-Apr;43(2):80-6. doi: 10.1590/0100-69912016002003.

17. Andreollo NA, Santos EF, Araújo MR, Lopes LR. Rat's age versus human's age: what is the relationship? Arq Bras Cir Dig. 2012 JanMar;25(1):49-51. doi: 10.1590/S0102-67202012000100011.
18. Sohn M, Füzesi L, Deutz F, Lagrange W, Kirkpatrick JC, Braun JC. Signet ring cell carcinoma in adenomatous polyp at site of ureterosigmoidostomy 16 years after conversion to ileal conduit. J Urol. 1990 Apr;143(4):805-7. PMID: 2156089.

19. Shamsuddin AK, Trump BF. Colon epithelium. I. Light microscopic, histochemical, and ultrastructural features of normal colon epithelium of male Fischer 344 rats. J Natl Cancer Inst. 1981 Feb;66(2):375-88. PMID: 6935485.

20. Alrawi SJ1, Schiff M, Carroll RE, Dayton M, Gibbs JF, Kulavlat M, Tan D, Berman K, Stoler DL, Anderson GR. Aberrant crypt foci. Anticancer Res. 2006 Jan-Feb;26(1A):107-19. PMID: 16475686.

21. Wargovich MJ, Brown VR, Morris J Aberrant crypt foci: the case for inclusion as a biomarker for colon cancer. Cancers (Basel). 2010 Sep 16;2(3):1705-16. doi: 10.3390/cancers2031705.

22. Léon MV, Sáenz FR. Focos de criptas aberrantes el comienzo de la hitoria. Gastroenterol Latinoam. 2007;18(4):383-9.

23. Daher N, Gautier R, Abourachid H, Decaens C, Bara J. Rat colonic carcinogenesis after ureterosigmoidostomy: pathogenesis and immunohistological study. J Urol. 1988 Jun;139(6):1331-6. PMID: 3286898

24. Pitot HC. The molecular biology of carcinogenesis. Cancer. 1993 Aug 1;72(3 Suppl):962-70. PMID: 8334671.

25. Vaish V, Sanyal SN. Chemopreventive effects of NSAIDs on cytokines and transcription factors during the early stages of colorectal cancer. Pharmacol Rep. 2011;63(5):1210-21. PMID: 22180364.

26. Magnuson BA, South EH, Exon JH, Dashwood RH, Xu M, Hendrix $\mathrm{K}$, Hubele S. Increased susceptibility of adult rats to azoxymethaneinduced aberrant crypt foci. Cancer Lett. 2000 Dec 20;161(2):18593. doi: 10.1016/S0304-3835(00)00609-1.

27. Furukawa F, Nishikawa A, Kitahori Y, Tanakamaru Z, Hirose M. Spontaneous development of aberrant crypt foci in F344 rats. J Exp Clin Cancer Res. 2002 Jun;21(2):197-201. PMID: 12148578.

28. Burlamaqui IM, Dornelas CA, Valença Júnior JT, Mota DM, Mesquita FJ, Veras LB, Vasconcelos PR, Rodrigues LV. Effect of a hyperlipidic diet rich in omegas 3, 6 and 9 on aberrant crypt formation in rat colonic mucosa. Acta Cir Bras. 2012 Jan;27(1):306. doi: 10.1590/S0102-86502012000100006.

\section{Correspondence:}

Profa. Dra. Conceição Aparecida Dornelas

Faculdade de Medicina, Departamento de Patologia e Medicina Legal

Rua Monsenhor Furtado, s/n

60441-750 Fortaleza - CE Brasil

Tel.: (55 85)3366-8300/3366-8301

eusoucondor@yahoo.com.br

Received: Aug 16, 2016

Review: Oct 19, 2016

Accepted: Nov 21, 2016

Conflict of interest: none

Financial source: none

${ }^{1}$ Research performed at Laboratory of Experimental, Department of Pathology and UNIFAC - Faculty of Medicine, Universidade Federal do Ceará (UFC), Brazil. Part of Master degree thesis, Postgraduate Program in Pathology. Tutor: Profa. Dra. Conceição Aparecida Dornelas. 